\title{
A Case Study of Undergraduate and Graduate Student Research in STEM Education
}

\author{
Lauren B. Birney ${ }^{1, *}$, Brian R. Evans ${ }^{1}$, Joyce Kong ${ }^{1}$, Vibhakumari Solanki², Elmer-Rico Mojica ${ }^{1}$, Gaurav \\ Kondapuram $^{1} \&$ Dimitrios Kaoutzanis ${ }^{1}$ \\ ${ }^{1}$ Pace University, New York, NY, USA \\ ${ }^{2}$ New York City Department of Education, New York, NY, USA \\ *Correspondence: School of Education, Pace University, One Pace Plaza, New York, NY, USA. Tel: \\ 1-212-346-1889. E-mail: lbirney@pace.edu
}

Received: December 9, 2020

Accepted: February 7, $2021 \quad$ Online Published: February 15, 2021

doi:10.5430/jct.v10n1p29

URL: https://doi.org/10.5430/jct.v10n1p29

\begin{abstract}
Student research in STEM education is an important learning component for both undergraduate and graduate students. It is not sufficient for students to learn passively in lecture-based classrooms without engaging and immersing themselves in the educational process through real-world research learning. Experiential learning for STEM students can involve conducting research, alongside and through the guidance of their professors, early in a student's undergraduate or graduate program. The authors consider such experiences to be the hallmark of a high-quality STEM education and something every student, undergraduate and graduate, should have during the course of their programs. The purpose of this case study is to document the faculty authors' experiences in student-faculty research and provide guidance and recommendations for best practices based upon the authors' experience, data, and literature findings. Moreover, the study presents the experience of the faculty authors' international student researchers in STEM with focus on two student researchers, one undergraduate and one graduate, who are international STEM. The students served as co-authors on this project. Findings from this case study indicate that students were highly engaged in the research process and found these skills valuable preparation for further study and career. Moreover, the students expressed enthusiasm and engagement for the research process.
\end{abstract}

Keywords: STEM education, experiential learning, undergraduate research, student-faculty research, international student, STEM career

\section{Introduction}

Students learn science and mathematics through "doing" in the way scientists and mathematicians conduct their own research, investigations, and practices (Brandt, 2016; Hoskins, 2019; Plank, 2017; Wilcox, Cruse, \& Clough, 2015). Not only do these experiences reflect the way in which STEM professionals conduct their work, but also they can be some of the most engaging and rewarding of a student's academic career (Mokter Hossain \& Robinson, 2012). The authors' own students have often commented on the value and joy of engaging in research, publication, and presentation of their work, and have expressed the research process as the best learning experiences they had during their programs.

The authors' University offers multiple support structures for undergraduate research. Faculty and student pairs have opportunities to apply for research funding through the Provost office with funds supporting research costs and student stipends in order to reduce the need for students to work unrelated part-time jobs to support themselves. One of the co-authors of this article was involved in launching a student travel conference fund that is one of the most generous funds in the nation for supporting student travel to present research at professional conferences. Moreover, there are multiple research programs at the University supporting student research through University and/or grant program funds such as Student Support Services TRIO program and the Center for Undergraduate Research Experiences (CURE). Annually, Pace University hosts a conference displaying student-faculty research. One of the authors of this article has served as a faculty judge at these events. 
In addition to the multiple support structures provided by the University, the University motto of Opportunitas (Opportunity) encourages students to pursue student research experience. Currently, for undergraduate students, only students in the Honors program are required to have a research projection senior capstone thesis. Students in the science programs commonly choose to do undergraduate research. This is very different from the experience of one of the STEM faculty authors who like the students come from outside of the United States. In one co-author's native country, thesis is a requirement to obtain an undergraduate degree in all fields of specialization. However, the non-requirement of a thesis for non-Honors students does not prevent them from conducting undergraduate research as the multiple structural supports at the University are available to many non-Honors students.

The purpose of this case study project is to document the faculty authors' experiences in student-faculty research and provide guidance and recommendations for best practices based upon the authors' experience, data, and literature findings. Uniquely, the faculty authors have engaged their own student researchers in the process as co-authors on this project, which provides the students with additional scholarship opportunities and experiences. The authors' objective is to provide faculty and student research teams with ideas based upon their own extensive experience either mentoring student research or engaging as student researchers.

Moreover, as previously mentioned, the student researchers are international students who bring international perspectives to their study and scholarship. Given the current political climate in the United States, the authors felt compelled to demonstrate the contributions their international students provide to STEM scholarship and inquiry.

\section{Background and Context for the Case Study}

The main catalyst for this case study was the need to create a STEM Career Guide for high school and college students who are interested in STEM careers. The guide will help students to understand career possibilities and to take the appropriate steps to achieve their STEM career goals. Hence, the authors recruited two STEM college students to conduct a literature search on STEM careers and steps needed to well position high school and college students for STEM careers. The process not only benefits future high school and college STEM students, but also the students conducting the search for two reasons. First, it helps the students find information relevant to their own career goals and objectives in a STEM field. Second, it engages them with a research project that provides experiential learning to complement their in classroom education.

An important aspect of student-faculty research is for the faculty member to be a good listener and allow latitude for the student to make decisions about the direction of the research. In this case, the faculty member serves more as a coach or guide through the process and allows students to construct their own knowledge (Piaget, 1971; Piaget \& Inhelder, 1972). Piaget (1971) was a pioneer in constructivism in which students construct their own knowledge and meaning guided by the teacher or professor. Faculty researchers can certainly provide explicit directions to student researchers without soliciting student feedback about the process for the project, but faculty can utilize a constructivist approach by giving students the opportunity to explore and construct their own knowledge. Students who make research decisions may have a stronger engagement and commitment to the project as critical stakeholders who make important research decisions (Gentile, Brenner, \& Stephens, 2017). This also prepares students for future research as authentic investigators in projects that interest them. Moreover, it can help to prepare them to answer their own research questions. One of the authors, who did not engage in research until graduate school, recalled his own faculty member's advice regarding choice of research topics. A student who plans to spend possibly several years on a topic needs to choose a topic that is relevant and interesting given the amount of time and effort that will be placed into the project. Research topics that are assigned to students may have a decline in interest over time.

The goal for the student researcher is to develop independent research skills and tools that will be transferable to the student's future pursuits, such as graduate studies or STEM careers. An important skill for a researcher is first to know where to find relevant and reliable information, which is not quite as easy as it may seem. Secondly, it is important for the researcher to be able to design and implement a study, and then be able to form valid and reliable conclusions that can be communicated to the broader academic community. The goal for student researchers is to help them develop into critical investigators who build upon current knowledge and develop new knowledge.

During the early stages for this project, the University had transitioned to remote learning due to the COVID-19 crisis, which meant the students and faculty involved in this project had to work collaboratively through video conferencing, email, and shared online documents. The remote process further demonstrated the ability to collaborate on a research team even if the team is unable to meet in person. The faculty and student authors used this experience to create processes for partnerships that can serve as a model for geographically dispersed research teams. This model built out 
of necessity provided additional direction for future collaborations that allow for a truly global model of research and collaboration given the reduced need for physical proximity for the research team.

\section{Theoretical Framework and Literature Review}

The conceptual framework for this study is grounded in Vygotsky's sociocultural theory of learning (Vygotsky, 1987) in which faculty and students form a community of learners through collaboration and investigation. Bandura's (1986, 1997) self-efficacy and social cognitive theory provides a foundation for which students develop through social interactions and student sense of self-efficacy. Moreover, Piaget's constructivist theory of learning forms the foundation of student-centered exploration through the research and scholarship process (Piaget, 1971; Piaget \& Inhelder, 1972).

The literature is replete with research on the value of student research in regard to learning, engagement, and retention with particular interest in engaging students from underrepresented groups in STEM (Hurtado, 2010; Rodenbusch, Hernandez, \& Dolan, 2016; Schultz et al., 2011; Strayhorn, 2010). Russell, Hancock, and McCullough (2007) argued that undergraduate research helps encourage students to consider graduate programs they may not have considered otherwise, and Linn, Palmer, Baranger, Gerard, and Stone (2015) indicated that student enthusiasm for learning is facilitated through student research, as the authors have found in their own interactions with student researchers. However, Russell (2008) cautioned that student research should be voluntary and not required since engagement with voluntary research had better benefits. Moreover, Harsh, Maltese, and Tai (2011) found the benefits from student research are long lasting and have long-term benefits for the students.

A secondary framework for this case study is the focus on contributions international students bring to STEM education and research in the United States. The student researchers in this case study both originate outside of the United States as many STEM students do within institutions of higher education in the United States (Congressional Research Service, 2019). Increasingly, there has been a steady rise in the number of international students studying STEM in the United States, and it was reported that from 1988 to 2016 the percentage of STEM degree recipients had doubled from $11 \%$ to $22 \%$, and has been higher in graduate degrees as well (Congressional Research Service, 2019). The 2018/2019 academic year represented an all-time high in the number of international STEM students (The Power of International Education, 2019). As of 2017, 72\% of international STEM students remained in the United States at least 10 years beyond their degree (Congressional Research Service, 2019), which provides invaluable benefits to the United States given the increasing need for critical STEM skills.

Moreover, the Programme for International Student Assessment (OECD, 2018) measures the reading ability, math and science literacy and other key skills among fifteen years old in a large number of countries both developed and developing. Every three years, it provides the most comprehensive and rigorous international assessment of student learning outcomes. The United States ranks 25th in mathematics and 18th in science in the latest PISA results (OECD, 2018). This is an improvement from the 2015 results (39th in mathematics and 25th in science). Recruiting international STEM students provides a larger pool of STEM career professionals needed for an increasingly technical society.

Numerous studies have supported the value of student-faculty research and several have offered evidence-based guidance on best practices in the student-faculty research process. Brownell et al. (2017) examined student progress on exams and student feedback surveys over a pilot introductory biology course with a research lab requirement over two years. Course examinations showed that students improved on their skills in data interpretation. The study also found that by having students exercise scientific thinking skills of collaboration, experimental repetition and data analysis as part of course requirements, they were able to better develop these skill sets that scientists use in practice.

Russell, Hancock, and McCullough (2007) collected responses from about 15,000 students over four surveys between 2003 to 2005 and found that undergraduate research experience may be improved by more effective mentoring programs. Results from an open-ended survey question revealed that faculty guidance coupled with the mentor's enthusiasm, organization, and research support can lead to more positive outcomes to a student's continuation in a STEM career pathway. The authors found their study was supported by the findings of Lopatto (2007), which replicated quantitative findings on the advantages of authentic research experiences for undergraduates. Lopatto concluded that students' experiences were enhanced by improvements in learning related to the research process, scientific problems, and lab techniques. Lopatto found that students reported improved tolerance for obstacles and working independently when they encounter difficulties since the research process requires them to problem solve and demonstrate perseverance. Research is not a linear process that guarantees a positive result. Oftentimes, researchers 
must revisit earlier steps in the process and make revisions, which means research is an iterative process that requires students to persist and spend considerable time in problem solving and revision.

\section{Methods}

This qualitative case study project serves to share the authors' student-faculty research experiences and examines two students' reflections on the effectiveness of research as part of their preparation for careers in the STEM fields. One undergraduate and one graduate student were recruited to assist with writing a STEM Career Guide for high school and college students, which required extensive literature review and investigation. The two students met routinely via video conferencing and email with their faculty mentors and research team for the duration of this project.

Each student conducted the literature review within the STEM areas that connected with their major: data science and mathematics. The students were guided to conduct research on academic articles on STEM career preparation. The students had access to online resources and the University Virtual Library. The students recorded their literature review on a Google Document that was shared among the researchers of this study. Finally, the students wrote summaries of each relevant academic article along with the citation of each article.

Following the research process for the STEM Career Guide, both students were interviewed independently. The student interviews conducted for this case study provides the data needed to address the purpose of the study, which was to document the experiences in student-faculty research. These data were used to provide guidance and recommendations for best practices in student-faculty research. The Results section provides student reflections on their process. Moreover, the students actively participated in video meetings with the authors of this paper to provide clarification and perspective on their experiences as student researchers.

The limitations of this case study is the sample size of two students who were selected to work with the faculty on this study. The present study should be considered exploratory and a catalyst for additional research on best practices in the student-faculty research process.

\section{Results}

The following documents the backgrounds and contexts for the two student researchers in which the students were given the opportunity to reflect upon their experiences as student researchers. The first student is a graduate student studying data science and the second student is an undergraduate student studying mathematics.

\subsection{Data Science Graduate Student}

The graduate student had been fascinated with science and technology at an early age as he observed aircrafts flying across the sky as a child. Watching the airplanes fly overhead helped him to consider a career as an airline pilot. These experiences led to an interest in studying engineering and his interest turned away from operating machines to designing and understanding how they work. Studying engineering and technology helped him understand how technological design and implementation worked, and gave him a new appreciation for engineering and computer science careers.

The graduate student recalled that while he was young he had experienced water shortages in his country. In college, he designed a project to mitigate water shortages through his studies of engineering by designing sensors and microcontrollers and how this can connect with automation systems. He participated in a national competition in which his idea was awarded third prize.

He found there were limited engineering opportunities, which led him to pursue his graduate degree in the United States. He is interested in a career in data science and specifically working with artificial intelligence in which he believes will have an important role in the future. He felt passionately that STEM careers play an essential role in human life development and in understanding environmental fluctuations, such as climate change. He acknowledged the importance of mathematics and problem solving in order to achieve his career goals.

The graduate student found that researching STEM has been impactful on his career path and has developed his analytical skills. He reported that with the rising scope in computer technology, his perspective on STEM, specifically data science, has revolutionized to where he sees the future of technology moving to SMART (Self-Monitoring Analysis and Reporting Technology).

Working with his faculty mentors, he found that conducting research on the STEM Career Guide provided him with an opportunity to apply his knowledge to improve his research skills. Specifically, he gained competency by using online 
research tools that allowed him to find the most relevant information that supported the goals of the project. This skill set will serve him well as he pursues independent research projects in his education and career.

\subsection{Mathematics Undergraduate Student}

The undergraduate student began his interest in mathematics while playing cards with his mother as he engaged with mental arithmetic to improve his game. He preferred conducting mathematical calculations compared to other academic pursuits such as reading and writing. Due to his talent in mathematics, his parents encouraged him to pursue the formal study of mathematics after he completed his mandatory military service in his home county.

In college, he began working as a mathematics tutor in the University's Learning Center. He found that other STEM majors were coming to the Learning Center for help with mathematics as it provided a foundation for study in other STEM fields such as chemistry. This helped him realize that understanding and applying mathematics opens many STEM areas for him, and over his college experience, he had become interested in the business applications of mathematics through actuarial science.

The undergraduate student was thrilled to be given an opportunity to apply what he was learning through investigating career pathways in STEM fields while contributing to the education of future students. The STEM Career Guide not only provides a research opportunity, but allows him to consider his own options in STEM careers while considering the best steps to take such as engaging in student-faculty research while still an undergraduate student.

He acknowledged that many students will change careers over time. The research, critical thinking, and quantitative skills he learned through the research project will be transferable and allow him to pursue various career options. While he is currently interested in actuarial science, he acknowledged his interest in virology as current events around COVID-19 had demonstrated the importance of STEM and the benefits it can bestow upon society such as eradicating a deadly pandemic. Engaging in research allowed him to develop a new perspective on research and his role as a researcher.

\section{Discussion and Conclusion}

The results of this study were encouraging. The two students in this study reported having the guidance and connections with people in their related career fields that helped them to better understand the job requirements, appropriate actions to take to prepare for their career choices, and provided insight into the available STEM career opportunities. They both reported that the research opportunities provided them with the experiences necessary to pursue their own STEM careers while also gaining a better understanding of the skill sets and experiences needed for those future careers. Moreover, both students indicated that the transferable skills learned in this process will be invaluable for their future STEM career pathway. The process has improved their appreciation and enthusiasm for the choices of majors and made what they are learning in the classroom more "real-world" and aligns with the best practices of "doing" science and mathematics (Brandt, 2016; Hoskins, 2019; Plank, 2017; Wilcox, Cruse, \& Clough, 2015). Additionally, the students had expressed an overall engaging and rewarding experience as indicated in the literature (Mokter Hossain \& Robinson, 2012). The faculty authors expect long-term benefits in building research confidence and self-efficacy (Bandura, 1986, 1997), which will be later explored in subsequent research.

The students expressed appreciation for the valuable skill sets they achieved in the research process, which enhances their engagement in STEM (Hurtado, 2010; Rodenbusch, Hernandez, \& Dolan, 2016; Lopatto, 2007; Schultz et al., 2011; Strayhorn, 2010). Moreover, their enthusiasm for STEM had risen as found in the literature (Linn, Palmer, Baranger, Gerard, \& Stone, 2015). Finally, as international students, the experiences they brought from their home countries to the University benefited them, their peers, and their professors.

The faculty authors of this study also learned more about mentoring and supporting student learning, and how listening to student researchers about their interests and aspirations provides the best collaborative relationship to be successful faculty mentors. The faculty authors acknowledged that witnessing the growth, enthusiasm, and interest from the students helped them realize that student-faculty research is the most rewarding aspect of their own careers.

It is important for senior faculty to include both student researchers and junior faculty in the research agendas. Providing opportunities such as these allows for growth both within academic departments as well as facilitating growth between the various schools within the University. Such intra-school opportunities ultimately allows faculty to create and establish new programs, train and facilitate new research for students, and continue to grow their own research trajectories. In turn, this promotes visibility for STEM careers for both graduates and undergraduates and provides beneficial advancement for all stakeholders involved in research study. 


\section{References}

Bandura, A. (1986). Social foundations of thought and action: A social cognitive theory. Englewood Cliffs, NJ: Prentice Hall.

Bandura, A. (1997). Self-efficacy: The exercise of control. New York, NY: W. H. Freeman.

Brandt, J. (2016). Mathematicians' and math educators' views on “doing mathematics." Problems, Resources, and Issues in Mathematics Undergraduate Studies, 26(8), 753-769. https://doi.org/10.1080/10511970.2016.1166408

Brownell, S. E., Hekmat-Scafe, D. S., Singla, V., Chandler Seawell, P., Conklin Imam, J. F., Eddy, S. L., Stearns, T., \& Cyert, M. S. (2015). A high-enrollment course-based undergraduate research experience improves student conceptions of scientific thinking and ability to interpret data. CBE Life Sciences Education, 14(2), 1-14. https://doi.org/10.1187/cbe.14-05-0092

Congressional Research Service. (2019). Foreign STEM students in the United States. Retrieved from https://crsreports.congress.gov/product/pdf/IF/IF11347

Gentile, J., Brenner, K., \& Stephens, A. (2017). Undergraduate research experiences for STEM students: Successes, challenges, and opportunities. New York, NY: The Natural Academies of Sciences, Engineering, and Medicine. Retrieved from https://frdo.unm.edu/sites/default/files/Undergraduate_Research_Experiences_for_STEM_Students.pdf

Harsh, J. A., Maltese, A. V., \& Tai, R. H. (2011). Undergraduate research experiences from a longitudinal perspective. Journal of College Science Teaching, 41(1), 84-91.

Hoskins, S. G. (2019). How I leaned to teach like a scientist. Science. https://doi.org/10.1126/science.caredit.aay3706

Hurtado, S. (2010). Degrees of success: Bachelor's degree completion rates among initial STEM majors, HERI research brief, Los Angeles, CA: Higher Education Research Institute at UCLA. Retrieved from https://www.heri.ucla.edu/nih/downloads/2010\%20-\%20Hurtado,\%20Eagan,\%20Chang\%20-\%20Degrees\%20o $\mathrm{f} \% 20$ Success.pdf

Linn, M. C., Palmer, E., Baranger, A., Gerard, E., \& Stone, E. (2015). Undergraduate research experiences: Impacts and opportunities. Science, 347(6222), 627-633. https://doi.org/10.1126/science.1261757

Lopatto, D. (2007). Undergraduate Research Experiences Support Science Career Decisions and Active Learning. CBE - Life Sciences Education 6(4), 297-306. https://doi.org/10.1187/cbe.07-06-0039

Mokter Hossain, M., \& Robinson, M. G. (2012). How to motivate US students to pursue STEM (Science, Technology, Engineering, and Mathematics) careers. US-China Education Review, 4, 442-451.

Organization for Economic Cooperation and Development (OECD, 2018). Programme for International Student Assessment (PISA) 2018 results. Retrieved from https://www.oecd.org/pisa/publications/pisa-2018-results.htm

Piaget, J. (1971). Psychology and epistemology: Towards a theory of knowledge. New York, NY: Grossman Publishers.

Piaget, J., \& Inhelder, B. (1972). The psychology of the child. New York, NY: Basic Books.

Plank, L. (2017). Getting students excited about STEM. Smartbrief. Retrieved from https://www.smartbrief.com/original/2017/08/getting-students-excited-about-stem

Rodenbusch, S., Hernandez, P. R., \& Dolan, E. L. (2016). Early engagement in course based research increases graduation rates and completion of science, engineering, and mathematics degrees. CBE Life Sci Educ, 15(2), 1-10. https://doi.org/10.1187/cbe.16-03-0117

Russell, S. H. (2008). Undergraduate research opportunities: Facilitating and encouraging the transition from student to scientist. In R. Taraban \& R. L. Blanton (Eds.), Creating effective undergraduate research programs in science (pp. 53-80). New York, NY: Teachers College Press.

Russell, S. H., Hancock, M. P., \& McCullough, J. (2007). Benefits of undergraduate research. Science, 316(5824), 548-549. https://doi.org/10.1126/science.1140384

Schultz, P. W. Hernandez, P. R., Woodcock, A., Estrada, M., Chance. R. C., Aguilar, M., \& Serpe, R. T. (2011). Patching the pipeline: reducing educational disparities in the sciences through minority training programs. Educational Evaluation and Policy Analysis, 33, 95-114. https://doi.org/10.3102\%2F0162373710392371

Strayhorn, T. L. (2010). Undergraduate research participation and STEM graduate degree aspirations among students 
of color. New Directions for Institutional Research, 2010(148), 85-93. https://doi.org/10.1002/ir.364

The Power of International Education. (2019). Number of international students in the United States hits all-time high. Retrieved https://www.iie.org/en/Why-IIE/Announcements/2019/11/Number-of-International-Students-in-the-United-Stat es-Hits-All-Time-High

Vygotsky, L. S. (1987). Thinking and speech. In R. W. Rieber \& A. S. Carton (Eds.), The collected works of Vygotsky, L. S. (Vol. 1): Problems of general psychology, 39-285. New York, NY: Plenum.

Wilcox, J., Kruse, J., \& Clough, M. (2015). Teaching Science through Inquiry. The Science Teacher, 82(6), 62-67. http://doi.org/10.2505/4/tst15_082_06_62

\section{Copyrights}

Copyright for this article is retained by the author(s), with first publication rights granted to the journal.

This is an open-access article distributed under the terms and conditions of the Creative Commons Attribution license (http://creativecommons.org/licenses/by/4.0/). 